\title{
Post-mortem whole-body magnetic resonance imaging of human fetuses: a comparison of 3-T vs. 1.5-T MR imaging with classical autopsy
}

Xin Kang ${ }^{1}$ MD, Mieke M. Cannie ${ }^{2,3}$ MD, PhD, Owen J. Arthurs ${ }^{4,5}$ MD, Valerie Segers ${ }^{6}$ MD, Catherine Fourneau ${ }^{6}$ MD, Elisa Bevilacqua ${ }^{1}$ MD, Teresa Cos Sanchez ${ }^{1}$ MD, Neil J. Sebire ${ }^{4,5}$ $\mathrm{MD}, \mathrm{PhD}$ and Jacques C. Jani ${ }^{1} \mathrm{MD}, \mathrm{PhD}$.

Departments of Obstetrics and Gynecology ${ }^{1}$, Radiology2, and Fetopathology ${ }^{6}$ University Hospital Brugmann, Université Libre de Bruxelles, Brussels, Belgium;

${ }^{3}$ Department of Radiology, UZ Brussel, Vrije Universiteit Brussel, Brussels, Belgium;

${ }^{4}$ Great Ormond Street Hospital for Children NHS Foundation Trust, London, UK;

${ }^{5}$ UCL Institute of Child Health, London, UK.

\section{Correspondence:}

Jacques C. Jani, MD, PhD

Department of Obstetrics and Gynecology

Fetal Medicine Unit

University Hospital Brugmann

Place A. Van Gehuchten 4

1020 Brussels

Belgium

Tel: +3224773631

Fax: + 3224772932

Email: jackjani@hotmail.com

Word count (excluding abstract): 3100 words. 
Post-mortem whole-body magnetic resonance imaging of human fetuses: a comparison of 3-T vs. 1.5-T MR imaging with classical autopsy

Type of manuscript: Original Research.

Key words: Post-mortem MRI, 3-Tesla, Accuracy, Classical post-mortem, Virtual autopsy. 


\begin{abstract}
Purpose:To prospectively compare diagnostic accuracy of fetal post-mortem wholebody MRI at 3-Tvs.1.5-T.

Methods:Between Oct-2012-Jul-2015, post-mortem MRI at 1.5-T and 3-T was performed in fetuses after miscarriage/stillbirth or termination. Clinical diagnoses made using MRI were assessed using a confidence diagnostic score and compared with classical autopsy to derive a diagnostic error score. The relation of diagnostic error for each organ group with gestational age was calculated and the comparison between 1.5-T with 3-T. Accuracy analysis was used to compare 1.5-T with 3-T.
\end{abstract}

Results:135 fetuses at 12-41 weeks underwent post-mortem MRI (followed by conventional autopsy in 92 fetuses). For all organ groups except the brain, and for both modalities, the diagnostic error decreased with gestation $(p<0.0001)$. The 3-T MRI diagnostic error was significantly lower than that of $1.5-\mathrm{T}$ for all anatomic structures and organ groups, except the orbits and brain. This difference was maintained for fetuses $<20$ weeks gestation. Moreover, 3-T was associated with fewer non-diagnostic scans and greater concordance with classical autopsy than 1.5-T MRI, especially for the thorax, heart and abdomen in fetuses $<20$ weeks.

Conclusion:Post-mortem fetal 3-T MRI improves confidence scores and overall accuracy as compared with 1.5-T, mainly for the thorax, heart, and abdomen of fetuses $<20$ weeks of gestation.

Word count: 200. 


\section{Key points:}

- In PM-MRI, diagnostic error using 3-T is lower than that with 1.5-T.

- In PM-MRI, diagnostic scan rate is higher using 3-T than 1.5-T.

- In PM-MRI, concordance with classical autopsy increases with 3-T.

- PM-MRI using 3-T is particularly interesting for thoracic and abdominal organs.

- PM-MRI using 3-T is particularly interesting for fetuses $<20$ weeks' gestation. 


\section{Introduction}

Technological advances in prenatal diagnostic tools have yielded the possibility of early diagnosis of fetal structural abnormalities, from the first trimester scan [1-3]. In the case of a severe abnormality, the parents often opt for termination of pregnancy and, in such circumstances as well as in the case of miscarriage, post-mortem examination by conventional autopsy remains critical for confirming or refuting the ante-mortem diagnosis and plays an important role in counseling parents concerning the recurrence risks for future pregnancies $[4,5]$. Unfortunately, perinatal autopsy rates are declining, reaching only $50 \%$ of eligible cases in some countries $[6,7]$. Factors associated with lack of parental consent include advanced gestational age at fetal death and religious considerations $[8,9]$. Furthermore, conventional autopsy might be difficult to perform in small fetuses at less than 20 weeks of gestation and calls for highly specialized fetal pathologists, who are often difficult to find [10].

In the last decade, efforts have been made to develop less invasive methods of postmortem examination. Post-mortem magnetic resonance (MR) imaging is now suggested as an acceptable alternative to conventional autopsy and has a parental acceptance of $79-99 \%[8,9]$. Recently, a prospective validation study for minimally invasive autopsy demonstrated a concordance of $89.3 \%$ with conventional autopsy [11]. This method included clinical history, external examination, post-mortem genetic and metabolic tests and post-mortem 1.5-T MR imaging. However, the concordance with autopsy for MR imaging alone was only $42.7 \%$ and $63 \%$, respectively, for fetuses at $\leq 24$ and $>24$ weeks of gestation.

MR imaging with a high-field magnet at 3-T has been developed for current clinical practice and its application has been studied in many medical fields $[12,13]$. However, few studies have considered its contribution to fetal post-mortem imaging [14-18] and we lack comparison with fetal whole-body post-mortem MR imaging at 1.5-T. 
The aim of our study was therefore to compare the image quality and diagnostic accuracy of fetal post-mortem whole-body MR imaging at 3-T and 1.5-T. 


\section{Materials and methods}

\section{Study participants and design}

The study was approved by the local ethics committee, and all written informed consent had been obtained from all parents. This was a single-institution prospective study, conducted at the Department of Radiology and Fetal Medicine Unit of the University Hospital ---, ---, ---, ---. Between October 2012 and July 2015, all consecutive patients suffering a fetal loss were invited to participate in this study whereby wholebody post-mortem MR imaging with 1.5-T and 3-T was performed in addition to conventional autopsy. Fetal deaths were related to termination, miscarriage or stillbirth. The fetuses were stored in refrigerated compartments at $4{ }^{\circ} \mathrm{C}$ before MR imaging examination.

\section{$\underline{\text { MR imaging examination }}$}

As soon as possible after delivery, and in a random order, consecutive whole-body MR imaging was performed using a 1.5-T magnet (Siemens Magnetom Avanto, Erlangen, Germany) and a 3-T magnet (Philips Achieva, Best, Netherlands).

Axial views of the head, and axial and coronal views of the body were acquired with high-resolution T2-weighted sequences. The parameters were adapted to obtain the best image quality within a maximum acquisition time of 60 minutes as we estimated that a longer acquisition time would be difficult to implement in future clinical practice. In this way, we hoped to reach the maximum capacity for both machines to allow the most equitable comparison. The typical acquisition parameters of the MR imaging protocols on both magnets are summarized in Table 1. 
$\underline{\text { Image evaluation }}$

Image contrast was evaluated for all cases by measuring the mean signal intensity in 16 anatomic areas with Image $\mathrm{J}$ (Version 1.46, National Institute of Health, US) by a single operator (first author) [10]: grey matter, thalamus, white matter, cartilage (head of humerus), bone (humeral diaphysis), muscle, intracardiac blood pool, myocardium, pericardial effusion, pleural effusion, lung, liver, adrenals, renal cortex, renal pelvis and spleen. Tissue contrast was calculated for 14 regions of interest (ROls) with the previously published formula [10]:

$$
\frac{\text { Signal intensity of area } A-\text { Signal intensity of area } B}{\text { Signal intensity of area } A+\text { Signal intensity of area } B}
$$

The clinical diagnoses of all cases were assessed independently by two radiologists $\left(2^{\text {nd }}\right.$ and $3^{\text {rd }}$ author, both with more than 10 years of experience in post-mortem MR imaging, at the start of the study). The 2 radiologists were blinded to the magnet used (1.5-T vs. 3-T), the results of the prenatal ultrasound examination, the other reader's report and the results of the conventional autopsy. The images obtained from both MR imaging machines were mixed and then presented in a random order.

A previously published confidence diagnostic score from 0 to 100 was given for 29 anatomic structures ( 0 definitely abnormal, 1-49 probably abnormal, 50 nondiagnostic, 51-99 probably normal and 100 definitely normal) [8]. In the case of concordance between operators, the mean score of the two operators was then calculated. In the case of discordance between operators, a consensus was reached and a new score was given. Abnormalities recognized as post-mortem changes were scored as normal.

\section{$\underline{\text { Post-mortem examination }}$}

As soon as possible after the post-mortem MR imaging, conventional autopsy was performed by two pathologists with more than 15 years of experience in fetal autopsy. According to current clinical practice, the pathologists were informed about the main 
prenatal findings related to fetal death in order to produce a full clinical report allowing counselling parents about their recurrence. The pathologists were blinded to the MR imaging examination results. The autopsy data were entered into a database that was separated from that used for the MR imaging examinations. The autopsy results were converted to the previously described diagnostic score for the same 29 anatomic structures analyzed with post-mortem MR imaging $(0=a b n o r m a l, 50=$ non diagnostic and $100=$ normal).

\section{Sample size}

Based on published data on the ability to visualize the four-chamber view of fetuses at $<20$ weeks of gestation with post-mortem fetal MR imaging with 3-T and 1.5-T(16), a power analysis performed before data collection revealed that at least 76 fetuses would be needed to detect a $5 \%$ difference in the number of visualized four-chamber views between the 2 modalities, with 95\% power. Given that these data described only the visualization of the four-chamber view of fetuses at $<20$ weeks of gestation, we increased the sample size to more than 90 cases with full autopsy.

\section{$\underline{\text { Statistical analysis }}$}

The diagnostic error at MR imaging was defined and calculated as the absolute value of the difference between the autopsy, when available, and MR imaging diagnostic score as represented by the following formula:

Diagnostic error $=\mid$ Autopsy diagnostic score - MR imaging diagnostic score $\mid$

The anatomic structures were then grouped to calculate the mean diagnostic error for the brain ( 5 anatomic structures), the face ( 3 anatomic structures), the thorax ( 3 anatomic structures), the heart ( 7 anatomic structures), the abdomen ( 8 anatomic structures) and the skeleton (3 anatomic structures). 
The proportion of non-diagnostic cases at classical autopsy for the brain as compared with other organs was compared using Mc Nemar's test of proportion for paired samples. The tissue contrasts of the 14 ROls were compared for 1.5-T and 3-T with the Wilcoxon test for paired samples.

The diagnostic errors for each organ group and gestational age were correlated using Spearman correlation analysis. Diagnostic errors for each anatomic structure and organ group were compared for 1.5-T and 3-T with the Wilcoxon test for paired samples.

For the accuracy analysis, the mean diagnostic score of post-mortem MR imaging and classical autopsy for each anatomic structure was transformed into categorical data as follows: 0-49 abnormal, 50 non-diagnostic, and 51-100 normal. When one anatomic structure was diagnosed as abnormal, the whole organ group was considered abnormal. When one anatomic structure was non-diagnostic and the other structures were normal, the organ group was considered non-diagnostic. When every structure was normal, the organ group was considered normal. The autopsy findings are set as the reference standard for comparison. We included the non-diagnostic cases in the group of false negatives for calculation of sensitivity and in the group of false positives for calculation of specificity.

Concordance was defined as the sum of true positives and true negatives divided by all cases including non-diagnostic cases. Discordance was defined as the sum of false negatives and false positives divided by all cases including non-diagnostic cases. The accuracy tests were compared with McNemar's test of proportion for paired samples. Post-hoc analyses were conducted for sensitivity and specificity comparison when the difference between 3-T and 1.5-T was no significant for thoracic, cardiac and abdominal organs in fetuses $<20$ weeks. 
Data are presented as medians unless mentioned otherwise. Data were analyzed with the statistical software packages STATA, version 12.0 (StataCorp LP, Texas) and Excel, version 9.0 (Microsoft, Redmond, WA). Post-hoc analysis for power and sample size was performed with R version 3.0.2 (The R Foundation for Statistical Computing, Vienna, Austria). Two-sided $P<0.05$ was considered statistically significant. 


\section{Results}

During the study period, 195 consecutive fetal losses occurred in our center but 135 fetuses were included in the study with post-mortem MR imaging performed 0-5 days after delivery and classical autopsy, when consent was obtained, 1-7 days after delivery (Fig 1). The median gestational age was 25.0 (range, 12.0-41.1) weeks. There were 44 fetuses of gestational age $<20$ weeks and $91 \geq 20$ weeks. For 92 of the 135 (68.1\%) fetuses included, the parents consented to classical whole-body post-mortem, with 32 at $<20$ and 60 at $\geq 20$ weeks of gestation. Of the 135 fetuses, $88(65.2 \%)$ had known prenatal abnormalities, $43(31.8 \%)$ had normal prenatal ultrasound imaging data and $4(3.0 \%)$ had no prenatal imaging. There was disagreement between readers in $12(4.4 \%)$ out of $270 \mathrm{MR}$ examination for which a consensus view was obtained.

The study flowchart and the diagnosis of each organ group with post-mortem MR imaging at 1.5-T and 3-T and classical autopsy are summarized in Fig 1. The proportion of non-diagnostic cases at classical autopsy was significantly higher for the brain with 39 out of 92 cases (42.4\%), as compared with the face, $6(6.5 \%)$, thorax, 4 (4.3\%), heart, 6 (6.5\%), abdomen, 1 (1.1\%) and skeleton, 4 (4.3\%) ( $p<0.0001$ for all). Among the non-diagnostic cases at classical autopsy for the brain, 32 of 39 (82.1\%) were diagnostic with $1.5-\mathrm{T}$ and 31 (79.5\%) with 3-T.

Tissue contrast was significantly increased with 3-T as compared with 1.5-T MR imaging for 9 out of the 14 studied ROI (Fig 2, and Fig 3-online).

For all organ groups except the brain, and for both modalities (1.5-T and 3-T), the diagnostic error and gestational age showed significant inverse correlation $(p<0.0001$ for all) (Fig 4). 
The diagnostic error was lower for 3-T than for 1.5-T MR imaging for all anatomic structures and organ groups, with the exception of the orbits and all structures of the brain (Table 2). This difference remained significant for fetuses at $<20$ weeks and $\geq$ 20 weeks of gestation, except for the face, for which the difference became nonsignificant at $\geq 20$ weeks of gestation (Fig 5).

Diagnostic accuracy for 3-T and 1.5-T MR imaging for all dataset and for each organ group are illustrated in Table 3. Overall, 3-T showed fewer non-diagnostic scans allowing an increase in sensitivity, specificity and concordance rate than 1.5-T MR imaging, and these differences are mainly present in fetuses $<20$ weeks $(p<0.01$ for all). (Fig 3,6-8).

In subgroups analysis by organ groups, there were fewer non-diagnostic scans at 3-T than 1.5-T of the face, thorax, heart and abdomen $(p<0.05)$. This reduction of nondiagnostic scans was significant for the face, thorax, heart and abdomen for fetuses $<$ 20 weeks $(p<0.05)$ (Fig 6), whereas for fetuses $\geq 20$ weeks, this reduction remained significant only for non-diagnostic abdominal scans $(p<0.05)$. The proportion of concordant diagnoses also increased for 3-T MR imaging for the thorax, heart and abdomen, mainly for fetuses aged $<20$ weeks ( $p<0.05$ for all), but not for those $\geq 20$ weeks. No significant differences were seen in sensitivity in this subgroup analysis, irrespective of gestational age group.

Post hoc power analysis with $80 \%$ power showed that to detect a significant difference in sensitivity between MR imaging at $1.5-\mathrm{T}$ vs. $3-\mathrm{T}$ in the group of fetuses $<20$ weeks, 61 with thoracic abnormalities, 32 with cardiac abnormalities and 45 with abdominal abnormalities would be needed. In this same group, to detect a significant difference in specificity between MR imaging at 1.5-T vs. 3-T, 33 fetuses with normal thorax and 35 with normal abdomen are needed. 


\section{Discussion}

Our study shows that 3-T had better image contrast, fewer non-diagnostic examinations, lower diagnostic error, and higher sensitivity, specificity and concordance than 1.5-T for fetal post-mortem whole-body MR imaging. The improvement is mainly in fetuses below 20 weeks of gestational age, in particular for thoracic organs including the heart and abdominal organs, but not the brain.

Since a higher field strength is accompanied by an increase in signal-to-noise ratio, better spatial resolution and thus more detailed imaging of fetal anatomy, attempts to improve image quality and diagnostic accuracy for small fetuses have focused on the use of higher-field magnets such as 3-T or 9.4-T [10,16-18]. In a study focusing on congenital heart defects (CHDs) including 24 fetuses at 11 to 20 weeks of gestation, MR imaging was performed with 1.5-T, 3-T and 9.4-T magnets prior to classical autopsy [16]. While only the cardiac situs and four-chamber view could be visualized in $62 \%$ and $25 \%$ of cases for $1.5-$ T MR imaging and $70 \%$ and $45 \%$ of cases on $3-T$ MR imaging respectively when the fetus was below 20 weeks of gestation, using MR imaging at 9.4 T, the cardiac situs, four-chamber view and the outflow tracts could be visualized in all fetuses irrespective of gestational age.

The major limitation of using MR imaging at 9.4-T is that such machines are currently only available in research units and have no other clinical application, thus limiting their use for post-mortem examination. In contrast, 3-T magnets are widely available in radiology and other clinical imaging units. A retrospective study including 58 fetal prenatal MR imaging examinations showed an overall advantage of 3-T for antenatal fetal imaging, with higher imaging scores for 3-T vs. 1.5-T MR imaging across different fetal anatomic structures [19]. However, while safety concerns may arise prenatally [20], there are none for post-mortem examination. 
Other fetal post-mortem imaging methods have been studied such as post-mortem ultrasound and post-mortem computerized tomography with or without contrast product for angiography. Post-mortem computerized tomography without contrast product has poor detection rate for major pathology in comparison to MR imaging [21]. Post-mortem computerized tomography angiography has shown promising results in feasibility studies [22,23], however validity studies are still needed. Ultrasound is a lowcost and easily accessible imaging method. Its application in fetal post-mortem examination has been suggested by recent pilot studies [24]. However, the sonographer was not blinded to the antenatal diagnosis and more studies are still needed.

The improvement of diagnostic accuracy with MR imaging at 3-T for cardiac abnormalities was suggested by Sandaite et al. in a retrospective study of 24 fetuses with $\mathrm{CHDs}$ assessed by post-mortem MR at 3-T at a median gestational age of 22.2 (range 12.5-34.6) weeks including 10 fetuses below 20 weeks. 3-T MR imaging was diagnostic for 12 / 13 (92.3\%) complex CHDs and for 6 / 11 (54.5\%) isolated CHDs [18]. Regarding fetuses $<20$ weeks, $3-T$ MR imaging was diagnostic in $50 \%$ of cases. The authors concluded that the technique was a valid diagnostic tool for CHDs in fetuses beyond 16 weeks of gestation.

Our study has prospectively and blindly evaluated the contribution of 3-T in wholebody post-mortem examination in comparison to 1.5-T MR imaging. We showed that 3-T has fewer non-diagnostic scans, better image contrast, lesser diagnosis error and better overall accuracy in comparison to 1.5-T MR imaging. The impact of 3-T is more relevant for fetuses $<20$ weeks. Regarding the heart, our study included 61 normal fetal hearts ( 14 fetuses $<20$ weeks) and 25 CHDs ( 13 fetuses $<20$ weeks). For the subgroup of fetuses <20 weeks, 3-T MR imaging had $37.0 \%$ of non-diagnostic scans, a specificity of $78.6 \%$ and a concordance rate of $55.6 \%$ with classical post-mortem 
whereas $1.5-\mathrm{T}$ imaging had $92.6 \%$ of non-diagnostic scans inducing $0 \%$ of concordance rate with classical post-mortem.

Our data did not demonstrate an improvement in brain imaging at 3-T over 1.5-T since tissue contrast, diagnostic error and diagnostic accuracy were comparable with both modalities. 1.5-T MRI has been shown to have sufficient image quality for most major brain abnormalities [25]. Furthermore, there are very few non-diagnostic scans for the brain with either 3-T and 1.5-T magnets, even when classical autopsy fails to provide a diagnosis because of marked autolysis [8]. These results encourage future use of post-mortem MR imaging as a first-line diagnostic tool in fetal brain malformations [11]. In our study using 3-T magnets, diagnostic accuracy for dysmorphologic features of the face was not significantly improved, but the diagnostic error was decreased. Dysmorphologic features are easily noted on non-invasive external examination of the body and do not typically require imaging.

Our data show similar sensitivity and specificity values for 1.5-T as compared with published data for the brain, thorax and musculoskeletal structures [25-27]. However, the sensitivity and specificity of abdominal structures at 1.5-T was lower in our study [28]. The large number of small fetuses included in our study could explain these results. Additionally, we included in our protocol analysis of the pancreas, which is often autolysed and therefore non-diagnostic, thus explaining the large number of nondiagnostic abdominal scans in our study.

We acknowledge that our study has some limitations. First, although our data include a large number of abnormalities, the sample size is not sufficient to demonstrate a significant difference in sensitivity between 3-T and 1.5-T for specific organs. For this purpose, the required number of cases with abnormalities per specific organ needs to be relatively high and can only be achieved in multicenter studies. Second, in our post- 
mortem evaluation we did not include clinical history, external examination, or postmortem genetic and metabolic tests, but only MR imaging, which led to underestimation of performance of a complete minimally invasive post-mortem using 3-T. On the other hand, our purpose was to focus on improving the contribution of MR imaging alone since the rest of investigation can be done equally with both modalities.

In conclusion, whole body post-mortem fetal MR imaging at 3-T has improved diagnostic accuracy compared to 1.5-T, mainly for fetuses $<20$ weeks, particularly for thoracic and abdominal organs. However, the diagnostic performance of MR imaging alone at 3-T for fetuses below 20 weeks of gestation may be considered insufficient for clinical practice, so the search for alternative techniques in this particular group is still justified. 


\section{References}

1. Syngelaki A, Chelemen T, Dagklis T, Allan L, Nicolaides KH (2011) Challenges in the diagnosis of fetal non-chromosomal abnormalities at 11-13 weeks. Prenat Diagn 31:90-102

2. Carvalho JS (2004) Fetal heart scanning in the first trimester. Prenat Diagn 24:1060-1067

3. Chaoui R, Benoit B, Mitkowska-Wozniak H, Heling KS, Nicolaides KH (2009) Assessment of intracranial translucency (IT) in the detection of spina bifida at the 11-13-week scan. Ultrasound Obstet Gynecol 34:249-252

4. Gordijn SJ, Erwich JJHM, Khong TY (2002) Value of the perinatal autopsy: critique. Pediatr Dev Pathol 5:480-488

5. Boyd PA, Tondi F, Hicks NR, Chamberlain PF (2004) Autopsy after termination of pregnancy for fetal anomaly: retrospective cohort study. BMJ 328:137

6. Thayyil S, Chitty LS, Robertson NJ, Taylor AM, Sebire NJ (2010) Minimally invasive fetal postmortem examination using magnetic resonance imaging and computerised tomography: current evidence and practical issues Prenat Diagn 30:713-718

7. Griffiths PD, Paley MNJ, Whitby EH (2005) Post-mortem MRI as an adjunct to fetal or neonatal autopsy. Lancet 365:1271-1273

8. Cannie M, Votino C, Moerman P et al (2012) Acceptance, reliability and confidence of diagnosis of fetal and neonatal virtuopsy compared with conventional autopsy: a prospective study. Ultrasound Obstet Gynecol 39:659-65

9. Kang X, Cos T, Guizani M, Cannie MM, Segers V, Jani JC (2014) Parental acceptance of minimally invasive fetal and neonatal autopsy compared with conventional autopsy. Prenat Diagn 34:1106-1110

10. Thayyil S, Cleary JO, Sebire NJ et al (2009) Post-mortem examination of human fetuses: a comparison of whole-body high-field MRI at $9.4 \mathrm{~T}$ with conventional MRI and invasive autopsy. Lancet 374:467-475

11. Thayyil S, Sebire NJ, Chitty LS et al (2013) Post-mortem MRI versus conventional autopsy in fetuses and children: a prospective validation study. Lancet 382:223233

12. Kuhl CK, Träber F, Schild HH (2008) Whole-body high-field-strength (3.0-T) MR Imaging in Clinical Practice. Part I. Technical considerations and clinical applications. Radiology 246:675-696

13. Kuhl CK, Träber F, Gieseke J et al (2008) Whole-body high-field-strength (3.0-T) MR imaging in clinical practice. Part II. Technical considerations and clinical applications. Radiology 247:16-35

14. Zhang Z, Liu S, Lin X et al. Development of fetal brain of 20 weeks gestational age: assessment with post-mortem Magnetic Resonance Imaging. Eur J Radiol $2011 ; 80(3): e 432-439$. 
15. Zhang Z, Liu S, Lin X et al (2011) Development of laminar organization of the fetal cerebrum at 3.0T and 7.0T: a postmortem MRI study. Neuroradiology 53:177-184

16. Votino C, Jani J, Verhoye $\mathrm{M}$ et al (2012) Postmortem examination of human fetal hearts at or below 20 weeks' gestation: a comparison of high-field MRI at 9.4 T with lower-field MRI magnets and stereomicroscopic autopsy. Ultrasound Obstet Gynecol 40:437-444

17. Sandaite I, De Catte L, Moerman P et al (2013) A morphometric study of the human fetal heart on post-mortem 3-tesla magnetic resonance imaging. Prenat Diagn 33:318-327

18. Sandaite I, Dymarkowski S, De Catte L et al (2014) Fetal heart pathology on postmortem 3-T magnetic resonance imaging. Prenat Diagn 34:223-229

19. Victoria T, Johnson AM, Edgar JC, Zarnow DM, Vossough A, Jaramillo D (2016) Comparison Between 1.5-T and 3-T MRI for Fetal Imaging: Is There an Advantage to Imaging With a Higher Field Strength? AJR Am J Roentgenol 206:195-201

20. Cannie MM, De Keyzer F, Van Laere S et al (2016) Potential Heating Effect in the Gravid Uterus by Using 3-T MR Imaging Protocols: Experimental Study in Miniature Pigs. Radiology 279:754-761

21. Arthurs OJ, Guy A, Thayyil S et al (2016) Comparison of diagnostic performance for perinatal and paediatric post-mortem imaging: CT versus MRI. Eur Radiol 2016;26:2327-2336.

22. Votino C, Cannie M, Segers V et al (2012) Virtual autopsy by computed tomographic angiography of the fetal heart: a feasibility study. Ultrasound Obstet Gynecol 39:679-684.

23. Sarda-Quarello L, Tuchtan L, Torrents $\mathrm{J}$ et al (2015) Perinatal death: Is there a place for post-mortem angio-CT? J Forensic Radiol Imaging 3:1-4.

24. Votino C, Bessieres B, Segers V et al (2014) Minimally invasive fetal autopsy using three-dimensional ultrasound: a feasibility study. Ultrasound Obstet Gynecol Aug 5.

25. Arthurs OJ, Thayyil S, Pauliah SS et al (2015) Diagnostic accuracy and limitations of post-mortem MRI for neurological abnormalities in fetuses and children. Clin Radiol 70:872-880

26. Arthurs OJ, Thayyil S, Olsen OE et al (2014) Diagnostic accuracy of post-mortem MRI for thoracic abnormalities in fetuses and children. Eur Radiol 24:2876-2884

27. Arthurs OJ, Thayyil S, Owens CM et al (2015) Diagnostic accuracy of post mortem MRI for abdominal abnormalities in foetuses and children. Eur J Radiol 84:474481

28. Arthurs OJ, Thayyil S, Addison S et al (2014) Diagnostic accuracy of postmortem MRI for musculoskeletal abnormalities in fetuses and children. Prenat Diagn 34:1254-1261 
Table 1. Typical acquisition parameters of T2-weighted turbo spin-echo MR images of the fetus on the 1.5 T and 3.0 T magnets. Saline bags were used to enhance the signal level, for the most part for smaller fetuses. Very small fetuses of gestational age less than 14 weeks were imaged in a $60 \mathrm{cc}$ syringe with saline solution.

\begin{tabular}{|c|c|c|}
\hline & $1.5 \mathrm{~T}$ MRI & 3.0 T MRI \\
\hline Coil & $\begin{array}{c}\text { For small fetuses } 4 \text {-ch flex coil, } \\
\text { otherwise a body coil }\end{array}$ & $\begin{array}{c}\text { For small fetuses, an 8-ch } \\
\text { SENSE wrist coil, } \\
\text { otherwise a body coil }\end{array}$ \\
\hline Number of slices & $25-111$ & $48-240$ \\
\hline Slice thickness (mm) & 2.0 & 1.2 \\
\hline Intersection gap (mm) & 0 & 0 \\
\hline FOV $\left(\mathbf{m m}^{2}\right)$ & $280 \times 210$ to $360 \times 280$ & $160 \times 128$ to $350 \times 280$ \\
\hline Matrix & $350 \times 420$ to $450 \times 560$ & $320 \times 213$ to $700 \times 467$ \\
\hline Effective echo time (ms) & 98 to 121 & 80 \\
\hline Repetition time (ms) & 6400 to 14830 & 4821 to 10607 \\
\hline Fourier Factor & 1 & 1 \\
\hline Voxel resolution $\left(\mathrm{mm}^{3}\right)$ & $0.8 \times 0.5 \times 2.0$ & $0.5 \times 0.6 \times 1.2$ \\
\hline Bandwidth (Hz/pixel) & 130 & 223 to 260 \\
\hline Acquisition time (min) & $\leq 60$ & $\leq 60$ \\
\hline NSA (NEX) & 2 to 11 & 3 to 9 \\
\hline
\end{tabular}


Table 2. Comparison of the median of the diagnostic error between 1.5-T and 3-T postmortem MR imaging.

\begin{tabular}{|c|c|c|c|}
\hline \multirow[b]{2}{*}{ Anatomic structure } & \multicolumn{3}{|c|}{ Median diagnosis error $(n=92)$} \\
\hline & 3-T (p25-p75) & 1.5-T (p25-p75) & $P$ value \\
\hline $\begin{array}{l}\text { Corpus callosum } \\
\text { Thalamus } \\
\text { Ventricles } \\
\text { Cortex } \\
\text { Cerebellum } \\
\end{array}$ & $\begin{array}{l}10(0-27.5) \\
17.5(7.5-35) \\
20(7.5-40) \\
22.5(7.5-45) \\
15(7.5-30) \\
\end{array}$ & $\begin{array}{l}10(5-20) \\
15(7.5-35) \\
17.5(5-40) \\
20(7.5-40) \\
17.5(7.5-35) \\
\end{array}$ & $\begin{array}{l}0.8857 \\
0.6086 \\
0.7791 \\
0.6928 \\
0.1253 \\
\end{array}$ \\
\hline Brain & $21.5(11-31.5)$ & $20.5(9-32)$ & 0.9211 \\
\hline $\begin{array}{l}\text { Orbits } \\
\text { Posterior nasal apertures } \\
\text { Palate } \\
\end{array}$ & $\begin{array}{l}17.5(7.5-50) \\
12.5(7.5-30) \\
15(10-30) \\
\end{array}$ & $\begin{array}{l}20(10-50) \\
15(10-40) \\
17.5(12.5-32.25) \\
\end{array}$ & $\begin{array}{l}0.4796 \\
0.0024 \\
0.0001 \\
\end{array}$ \\
\hline Face & $19.17(10-36.67)$ & $25(11.67-39.17)$ & 0.0005 \\
\hline $\begin{array}{l}\text { Trachea } \\
\text { Thymus } \\
\text { Lung } \\
\end{array}$ & $\begin{array}{l}10(5-25) \\
12.5(5-30) \\
10(5-20) \\
\end{array}$ & $\begin{array}{l}12.5(6.25-32.25) \\
15(10-37.5) \\
12.5(5-26.25) \\
\end{array}$ & $\begin{array}{l}<0.0001 \\
0.0003 \\
<0.0001 \\
\end{array}$ \\
\hline Thorax & $10.83(6.67-27.92)$ & $14.58(8.33-43.33)$ & $<0.0001$ \\
\hline $\begin{array}{l}\text { Cardiac ventricles } \\
\text { Atria } \\
\text { Cardiac septum } \\
\text { Aorta } \\
\text { Pulmonary artery } \\
\text { Systemic veins } \\
\text { Pulmonary veins } \\
\end{array}$ & $\begin{array}{l}20(10-35) \\
20(10-32.5) \\
15(6.25-28.75) \\
17.5(7.5-28.75) \\
17.5(7.5-35) \\
17.5(5-28.75) \\
21.25(7.5-40) \\
\end{array}$ & $\begin{array}{l}25(15-45) \\
25(15-45) \\
21.25(11.25-41.25) \\
25(13.75-45) \\
25(13.75-50) \\
20(10-45) \\
32.5(17.5-50) \\
\end{array}$ & $\begin{array}{l}0.0002 \\
<0.0001 \\
0.0001 \\
<0.0001 \\
<0.0001 \\
<0.0001 \\
<0.0001 \\
\end{array}$ \\
\hline Heart & $20(9.29-35.18)$ & $26.25(14.82-43.21)$ & $<0.0001$ \\
\hline $\begin{array}{l}\text { Liver } \\
\text { Spleen } \\
\text { Pancreas } \\
\text { Gallbladder } \\
\text { Bowels } \\
\text { Adrenals } \\
\text { Kidneys } \\
\text { Bladder } \\
\text { Genitals } \\
\end{array}$ & $\begin{array}{l}10(7.55-25) \\
10(5-25) \\
31.25(17.5-50) \\
15(7.5-30) \\
10(5-25) \\
10(10-25) \\
10(5-25) \\
11.25(6.25-25) \\
10(5-40) \\
\end{array}$ & $\begin{array}{l}15(10-27.5) \\
12.5(7.5-33.75) \\
45(30-50) \\
18.75(12.5-40) \\
15(6.25-33.75) \\
15(10-30) \\
12.5(7.5-32.5) \\
15(7.5-35) \\
13.75(7.5-50) \\
\end{array}$ & $\begin{array}{l}0.0003 \\
<0.0001 \\
<0.0001 \\
<0.0001 \\
0.006 \\
<0.0001 \\
0.0003 \\
<0.0001 \\
0.0016 \\
\end{array}$ \\
\hline Abdomen & $19.44(10.42-29.58)$ & 22.64 (13.33-36.25) & $<0.0001$ \\
\hline $\begin{array}{l}\text { Spine } \\
\text { Vertebra } \\
\text { Musculoskeletal system } \\
\end{array}$ & $\begin{array}{l}12.5(7.5-25) \\
10(5-22.5) \\
10(7.5-30) \\
\end{array}$ & $\begin{array}{l}15(10-30) \\
12.5(7.5-30) \\
15(7.5-40) \\
\end{array}$ & $\begin{array}{l}<0.0001 \\
0.0016 \\
0.0117 \\
\end{array}$ \\
\hline Skeleton & $11.67(4.5-33.33)$ & $16.67(9.17-35.83)$ & 0.0001 \\
\hline
\end{tabular}


Table 3. (ONLINE) Accuracy test comparison between 1.5-T and 3-T post-mortem MR imaging. * Exact C.I.

\begin{tabular}{|c|c|c|c|c|c|c|c|c|c|}
\hline & \multicolumn{3}{|c|}{ Overall } & \multicolumn{3}{|c|}{$<20$ weeks } & \multirow[b]{2}{*}{ 3.0-T } & \multirow[b]{2}{*}{$1.5-\mathrm{T}$} & \multirow[b]{2}{*}{$p$} \\
\hline & $3.0-\mathrm{T}$ & $1.5-\mathrm{T}$ & p & 3.0-T & $1.5-\mathrm{T}$ & p & & & \\
\hline \multicolumn{10}{|l|}{ All organs } \\
\hline Non-diagnostic (\%) & $\begin{array}{c}10.0(49 / 492) \\
{[7.3-12.6]}\end{array}$ & $\begin{array}{c}20.3(100 / 492) \\
{[16.8-23.9]} \\
\end{array}$ & $<0.0001$ & $\begin{array}{c}30.4(48 / 158) \\
{[23.2-37.6]}\end{array}$ & $\begin{array}{c}53.8(85 / 158) \\
{[46.0-61.6]}\end{array}$ & $<0.0001$ & $\begin{array}{c}0.3(1 / 334) \\
{[0-0.9]}\end{array}$ & $\begin{array}{c}4.5(15 / 334) \\
{[2.3-6.7]} \\
\end{array}$ & 0.0005 \\
\hline Sensitivity (\%) & $\begin{array}{c}51.7(74 / 143) \\
{[43.6-59.9]}\end{array}$ & $\begin{array}{c}45.5(65 / 143) \\
{[37.3-53.6]}\end{array}$ & 0.0225 & $\begin{array}{c}34.6(18 / 52) \\
{[21.7-47.6]} \\
\end{array}$ & $\begin{array}{c}17.3(9 / 52) \\
{[7.0-27.6]} \\
\end{array}$ & 0.0039 & $\begin{array}{c}61.5(56 / 91) \\
{[51.5-71.5]} \\
\end{array}$ & $\begin{array}{c}61.5(56 / 91) \\
{[51.5-71.5]} \\
\end{array}$ & 1 \\
\hline Specificity (\%) & $\begin{array}{c}87.4(305 / 349) \\
{[83.9-90.9]}\end{array}$ & $\begin{array}{c}77.9(272 / 349) \\
{[73.6-82.3]} \\
\end{array}$ & $<0.0001$ & $\begin{array}{c}65.1(69 / 106) \\
{[56.0-74.2]} \\
\end{array}$ & $\begin{array}{c}45.3(48 / 106) \\
{[35.8-54.8]}\end{array}$ & $<0.0001$ & $\begin{array}{c}97.1(236 / 243) \\
{[95.0-99.2]} \\
\end{array}$ & $\begin{array}{c}92.2(224 / 243) \\
{[88.8-95.6]} \\
\end{array}$ & 0.0018 \\
\hline Concordant (\%) & $\begin{array}{c}77.0(379 / 492) \\
{[73.3-80.8]} \\
\end{array}$ & $\begin{array}{c}68.5(337 / 492) \\
{[64.4-72.6]}\end{array}$ & $<0.0001$ & $\begin{array}{c}55.1(87 / 158) \\
{[47.3-62.8]} \\
\end{array}$ & $\begin{array}{c}36.1(57 / 158) \\
{[28.6-43.6]}\end{array}$ & $<0.0001$ & $\begin{array}{c}87.4(292 / 334) \\
{[83.9-91.0]} \\
\end{array}$ & $\begin{array}{c}83.8(280 / 334) \\
{[79.9-87.8]} \\
\end{array}$ & 0.0118 \\
\hline Discordant (\%) & $\begin{array}{c}13.0(64 / 492) \\
{[10.0-16.0]} \\
\end{array}$ & $\begin{array}{c}11.2(56 / 492) \\
{[8.4-14.0]} \\
\end{array}$ & 0.0784 & $\begin{array}{c}14.6(23 / 158) \\
{[9.1-20.1]} \\
\end{array}$ & $\begin{array}{c}10.1(16 / 158) \\
{[5.4-14.8]}\end{array}$ & 0.0923 & $\begin{array}{c}12.3(41 / 334) \\
{[8.8-15.8]} \\
\end{array}$ & $\begin{array}{c}12.0(40 / 334) \\
{[8.5-15.5]} \\
\end{array}$ & 1 \\
\hline \multicolumn{10}{|l|}{ Brain } \\
\hline Non-diagnostic (\%) & $\begin{array}{c}5.6(3 / 53) \\
{[1.2-15.7]^{*}}\end{array}$ & $\begin{array}{c}5.6(3 / 53) \\
{[1.2-15.7]^{*}}\end{array}$ & 1 & $\begin{array}{l}18.8(3 / 16) \\
{[4.1-45.7]^{*}}\end{array}$ & $\begin{array}{l}18.8(3 / 16) \\
{[4.1-45.7]^{*}}\end{array}$ & 1 & $\begin{array}{l}0(0 / 37) \\
{[0-9.5]}\end{array}$ & $\begin{array}{c}0(0 / 37) \\
{[0-9.5]}\end{array}$ & 1 \\
\hline Sensitivity (\%) & $\begin{array}{l}83.3(15 / 18) \\
{[58.6-96.4]^{*}}\end{array}$ & $\begin{array}{l}83.3(15 / 18) \\
{[58.6-96.4]^{*}}\end{array}$ & 1 & $\begin{array}{c}100(2 / 2) \\
{[15.8-100]^{*}}\end{array}$ & $\begin{array}{c}100(2 / 2) \\
{[15.8-100]^{*}}\end{array}$ & 1 & $\begin{array}{l}81.3(13 / 16) \\
{[54.4-96.0]^{*}}\end{array}$ & $\begin{array}{l}81.3(13 / 16) \\
{[54.4-96.0]^{*}}\end{array}$ & 1 \\
\hline Specificity (\%) & $\begin{array}{c}80(28 / 35) \\
{[63.1-91.6]^{*}}\end{array}$ & $\begin{array}{l}85.7(30 / 35) \\
{[69.7-95.2]^{*}}\end{array}$ & 0.5 & $\begin{array}{c}50(7 / 14) \\
{[23.0-77.0]^{*}}\end{array}$ & $\begin{array}{c}64.3(9 / 14) \\
{[35.1-87.2]^{*}}\end{array}$ & 0.5 & $\begin{array}{l}100(21 / 21) \\
{[83.9-100]^{*}}\end{array}$ & $\begin{array}{l}100(21 / 21) \\
{[83.9-100]^{*}}\end{array}$ & 1 \\
\hline Concordant (\%) & $\begin{array}{l}81.1(43 / 53) \\
{[68.0-90.6]^{*}}\end{array}$ & $\begin{array}{l}84.9(45 / 53) \\
{[72.4-93.3]^{*}}\end{array}$ & 0.5 & $\begin{array}{c}56.3(9 / 16) \\
{[29.9-80.3]^{*}}\end{array}$ & $\begin{array}{l}68.8(11 / 16) \\
{[41.3-89.0]^{*}}\end{array}$ & 0.5 & $\begin{array}{l}91.9(34 / 37) \\
{[78.1-98.3]^{*}}\end{array}$ & $\begin{array}{l}91.9(34 / 37) \\
{[78.1-98.3]^{*}}\end{array}$ & 1 \\
\hline Discordant (\%) & $\begin{array}{l}13.2(7 / 53) \\
{[5.5-25.3]^{*}}\end{array}$ & $\begin{array}{c}9.4(5 / 53) \\
{[3.1-20.7]^{*}} \\
\end{array}$ & 0.5 & $\begin{array}{c}25(4 / 16) \\
{[7.3-52.4]^{*}} \\
\end{array}$ & $\begin{array}{l}12.5(2 / 16) \\
{[1.6-38.4]^{*}} \\
\end{array}$ & 0.5 & $\begin{array}{l}8.1(3 / 37) \\
{[1.7-21.9]^{*}} \\
\end{array}$ & $\begin{array}{c}8.1(3 / 37) \\
{[1.7-21.9]^{*}} \\
\end{array}$ & 1 \\
\hline \multicolumn{10}{|l|}{ Face } \\
\hline Non-diagnostic (\%) & $\begin{array}{c}5.8(5 / 86) \\
{[1.9-13.1]^{*}}\end{array}$ & $\begin{array}{c}14.0(12 / 86) \\
{[6.6-21.3]}\end{array}$ & 0.0156 & $\begin{array}{l}17.9(5 / 28) \\
{[6.1-36.9]^{*}}\end{array}$ & $\begin{array}{c}39.3(11 / 28) \\
{[21.2-57.4]}\end{array}$ & 0.0313 & $\begin{array}{l}0(0 / 58) \\
{[0-6.2]}\end{array}$ & $\begin{array}{l}1.7(1 / 58) \\
{[0.0-9.2]^{*}}\end{array}$ & 1 \\
\hline Sensitivity (\%) & $\begin{array}{c}26.9(7 / 26) \\
{[11.6-47.8]^{*}}\end{array}$ & $\begin{array}{l}19.2(5 / 26) \\
{[6.6-39.4]^{*}}\end{array}$ & 0.625 & $\begin{array}{c}22.2(2 / 9) \\
{[2.8-60.0]^{*}}\end{array}$ & $\begin{array}{c}0(0 / 9) \\
{[0-33.6]}\end{array}$ & 0.5 & $\begin{array}{c}29.4(5 / 17) \\
{[10.3-56.0]^{*}}\end{array}$ & $\begin{array}{c}29.4(5 / 17) \\
{[10.3-56.0]^{*}}\end{array}$ & 1 \\
\hline Specificity (\%) & $\begin{array}{c}95(57 / 60) \\
{[86.1-99.0]^{*}}\end{array}$ & $\begin{array}{l}88.3(53 / 60) \\
{[77.4-95.2]^{*}}\end{array}$ & 0.125 & $\begin{array}{c}84.2(16 / 9) \\
{[60.4-96.6]^{*}}\end{array}$ & $\begin{array}{l}73.7(14 / 19) \\
{[48.8-90.9]^{*}}\end{array}$ & 0.5 & $\begin{array}{l}97.6(40 / 41) \\
{[87.1-99.9]^{*}} \\
\end{array}$ & $\begin{array}{l}95.1(39 / 41) \\
{[83.5-99.4]^{*}}\end{array}$ & 1 \\
\hline Concordant (\%) & $\begin{array}{c}73.3(63 / 86) \\
{[65.2-83.6]}\end{array}$ & $\begin{array}{l}67.4(58 / 86) \\
{[57.5-77.4]}\end{array}$ & 0.125 & $\begin{array}{l}64.3(18 / 28) \\
{[44.1-81.4]^{*}}\end{array}$ & $\begin{array}{c}50(14 / 28) \\
{[31.5-68.5]}\end{array}$ & 0.1 & $\begin{array}{c}77.6(45 / 58) \\
{[66.9-88.3]}\end{array}$ & $\begin{array}{c}75.9(44 / 58) \\
{[64.9-86.9]}\end{array}$ & 1 \\
\hline Discordant (\%) & $\begin{array}{c}20.9(18 / 86) \\
{[12.9-31.1]} \\
\end{array}$ & $\begin{array}{c}18.6(16 / 86) \\
{[10.4-26.8]} \\
\end{array}$ & 0.625 & $\begin{array}{l}17.9(5 / 28) \\
{[6.1-36.9]^{*}} \\
\end{array}$ & $\begin{array}{l}10.7(3 / 28) \\
{[2.3-28.2]^{*}}\end{array}$ & 0.5 & $\begin{array}{l}22.4(13 / 58) \\
{[11.7-33.2]} \\
\end{array}$ & $\begin{array}{l}24.1(14 / 58) \\
{[13.1-35.2]} \\
\end{array}$ & 1 \\
\hline \multicolumn{10}{|l|}{ Thorax } \\
\hline Non-diagnostic (\%) & $\begin{array}{l}10.2(9 / 88) \\
{[4.8-18.5]^{*}}\end{array}$ & $\begin{array}{c}20.4(18 / 88) \\
{[12.0-28.9]}\end{array}$ & 0.0117 & $\begin{array}{c}32.1(9 / 28) \\
{[15.9-52.4]^{*}}\end{array}$ & $\begin{array}{c}60.7(17 / 28) \\
{[42.6-78.8]} \\
\end{array}$ & 0.0215 & $\begin{array}{l}0(0 / 60) \\
{[0-6.0]}\end{array}$ & $\begin{array}{l}1.7(1 / 60) \\
{[0.0-8.9]^{*}}\end{array}$ & 1 \\
\hline Sensitivity (\%) & $\begin{array}{c}44.4(8 / 18) \\
{[21.5-69.2]^{*}}\end{array}$ & $\begin{array}{c}33.3(6 / 18) \\
{[13.3-59.0]^{*}}\end{array}$ & 0.5 & $\begin{array}{c}12.5(1 / 8) \\
{[0.3-52.7]^{*}}\end{array}$ & $\begin{array}{c}0(0 / 8) \\
{[0-36.9]}\end{array}$ & 1 & $\begin{array}{c}70(7 / 10) \\
{[34.8-93.3]^{*}}\end{array}$ & $\begin{array}{c}60(6 / 10) \\
{[26.2-87.8]^{*}}\end{array}$ & 1 \\
\hline Specificity (\%) & $\begin{array}{c}90(63 / 70) \\
{[80.5-95.9]^{*}}\end{array}$ & $\begin{array}{c}81.4(57 / 70) \\
{[72.3-90.5]}\end{array}$ & 0.07 & $\begin{array}{c}70(14 / 20) \\
{[45.7-88.1]^{*}}\end{array}$ & $\begin{array}{c}40(8 / 20) \\
{[19.2-64.0]^{*}}\end{array}$ & 0.07 & $\begin{array}{c}98(49 / 50) \\
{[89.4-100]^{*}}\end{array}$ & $\begin{array}{c}98(49 / 50) \\
{[89.4-100]^{*}}\end{array}$ & 1 \\
\hline Concordant (\%) & $\begin{array}{c}80.7(71 / 88) \\
{[72.4-88.9]}\end{array}$ & $\begin{array}{c}81.6(83 / 88) \\
{[62.2-81.0]}\end{array}$ & 0.0215 & $\begin{array}{c}53.6(15 / 28) \\
{[35.1-72.0]}\end{array}$ & $\begin{array}{c}28.6(8 / 28) \\
{[13.2-48.7]^{*}}\end{array}$ & 0.0391 & $\begin{array}{l}93.3(56 / 60) \\
{[83.8-98.2]^{*}}\end{array}$ & $\begin{array}{l}91.7(55 / 60) \\
{[81.6-97.2]^{*}}\end{array}$ & 1 \\
\hline Discordant (\%) & $\begin{array}{c}9.1(8 / 88) \\
{[4.0-17.1]^{*}} \\
\end{array}$ & $\begin{array}{c}8.0(7 / 88) \\
{[3.3-15.7]^{*}} \\
\end{array}$ & 1 & $\begin{array}{l}14.3(4 / 28) \\
{[4.0-32.7]^{*}}\end{array}$ & $\begin{array}{l}10.7(3 / 28) \\
{[2.3-28.2]^{*}}\end{array}$ & 1 & $\begin{array}{c}6.7(4 / 60) \\
{[1.9-16.2]^{*}} \\
\end{array}$ & $\begin{array}{c}6.7(4 / 60) \\
{[1.9-16.2]^{*}} \\
\end{array}$ & 1 \\
\hline \multicolumn{10}{|l|}{ Heart } \\
\hline Non-diagnostic (\%) & $\begin{array}{l}11.6(10 / 86) \\
{[5.7-20.4]^{*}}\end{array}$ & $\begin{array}{c}33.7(29 / 86) \\
{[23.7-43.7]}\end{array}$ & $<0.0001$ & $\begin{array}{l}37.0(10 / 27) \\
{[19.4-57.6]^{*}}\end{array}$ & $\begin{array}{l}92.6(25 / 27) \\
{[75.7-99.1]^{*}}\end{array}$ & 0.0001 & $\begin{array}{l}0(0 / 59) \\
{[0-6.1]}\end{array}$ & $\begin{array}{c}6.8(4 / 59) \\
{[1.9-16.5]^{*}}\end{array}$ & 0.125 \\
\hline Sensitivity (\%) & $\begin{array}{l}48(12 / 25) \\
{[28.4-67.6]}\end{array}$ & $\begin{array}{c}36(9 / 25) \\
{[18.0-57.5]^{*}}\end{array}$ & 0.375 & $\begin{array}{l}23.1(3 / 13) \\
{[5.0-53.8]^{*}}\end{array}$ & $\begin{array}{l}0(0 / 13) \\
{[0-24.7]}\end{array}$ & 0.3 & $\begin{array}{c}75(9 / 12) \\
{[42.8-94.5]^{*}}\end{array}$ & $\begin{array}{c}75(9 / 12) \\
{[42.8-94.5]^{*}}\end{array}$ & 1 \\
\hline Specificity (\%) & $\begin{array}{l}95.1(58 / 61) \\
{[86.3-99.0]^{*}}\end{array}$ & $\begin{array}{c}70.5(43 / 61) \\
{[59.1-81.9]}\end{array}$ & 0.0001 & $\begin{array}{l}78.6(11 / 14) \\
{[49.2-95.3]^{*}}\end{array}$ & $\begin{array}{l}0(0 / 14) \\
{[0-23.2]}\end{array}$ & 0.001 & $\begin{array}{l}100(47 / 47) \\
{[92.5-100]^{*}}\end{array}$ & $\begin{array}{l}91.5(43 / 47) \\
{[79.6-97.6]^{*}}\end{array}$ & 0.125 \\
\hline Concordant (\%) & $\begin{array}{c}81.4(70 / 86) \\
{[73.2-89.6]} \\
\end{array}$ & $\begin{array}{c}60.5(52 / 86) \\
{[50.1-70.8]}\end{array}$ & $<0.0001$ & $\begin{array}{c}51.9(14 / 27) \\
{[33.0-70.7]} \\
\end{array}$ & $\begin{array}{l}0(0 / 27) \\
{[0-12.8]}\end{array}$ & 0.0001 & $\begin{array}{l}94.9(56 / 59) \\
{[85.9-98.9]^{*}} \\
\end{array}$ & $\begin{array}{l}88.1(52 / 59) \\
{[77.1-95.1]^{*}} \\
\end{array}$ & 0.2188 \\
\hline Discordant (\%) & $\begin{array}{c}7.0(6 / 86) \\
{[2.6-14.6]^{*}} \\
\end{array}$ & $\begin{array}{c}5.8(5 / 86) \\
{[1.9-13.1]^{*}} \\
\end{array}$ & 1 & $\begin{array}{l}11.1(3 / 27) \\
{[2.4-29.2]^{*}} \\
\end{array}$ & $\begin{array}{c}7.4(2 / 27) \\
{[0.9-24.3]^{*}} \\
\end{array}$ & 1 & $\begin{array}{c}5.1(3 / 59) \\
{[1.1-14.2]^{*}} \\
\end{array}$ & $\begin{array}{c}5.1(3 / 59) \\
{[1.1-14.2]^{*}} \\
\end{array}$ & 1 \\
\hline \multicolumn{10}{|l|}{ Abdomen } \\
\hline Non-diagnostic (\%) & $\begin{array}{c}17.6(16 / 91) \\
{[9.8-25.4]}\end{array}$ & $\begin{array}{c}36.3(33 / 91) \\
{[26.4-46.1]}\end{array}$ & 0.0001 & $\begin{array}{c}48.4(15 / 31) \\
{[30.8-66.0]}\end{array}$ & $\begin{array}{l}77.4(24 / 31) \\
{[58.9-90.4]^{*}}\end{array}$ & 0.0039 & $\begin{array}{l}1.7(1 / 60) \\
{[0.0-8.9]^{*}}\end{array}$ & $\begin{array}{c}15(9 / 60) \\
{[7.1-26.6]^{*}}\end{array}$ & 0.0215 \\
\hline Sensitivity (\%) & $\begin{array}{c}56.3(18 / 32) \\
{[39.1-73.4]} \\
\end{array}$ & $\begin{array}{c}53.1(17 / 32) \\
{[35.8-70.4]}\end{array}$ & 1 & $\begin{array}{c}50(6 / 12) \\
{[21.1-78.9]^{*}}\end{array}$ & $\begin{array}{l}33.3(4 / 12) \\
{[9.9-65.1]^{*}}\end{array}$ & 0.5 & $\begin{array}{c}60(12 / 20) \\
{[38.5-81.5]}\end{array}$ & $\begin{array}{c}65(13 / 20) \\
{[40.8-84.6]^{*}}\end{array}$ & 1 \\
\hline Specificity (\%) & $\begin{array}{c}72.9(43 / 59) \\
{[61.5-84.2]} \\
\end{array}$ & $\begin{array}{c}54.2(32 / 59) \\
{[41.5-97.0]}\end{array}$ & 0.0034 & $\begin{array}{c}31.6(6 / 19) \\
{[12.6-56.6]^{*}}\end{array}$ & $\begin{array}{l}10.5(2 / 19) \\
{[1.3-33.1]^{*}}\end{array}$ & 0.1 & $\begin{array}{l}92.5(37 / 40) \\
{[79.6-98.4]^{*}}\end{array}$ & $\begin{array}{c}75(30 / 40) \\
{[58.8-87.3\}^{*}}\end{array}$ & 0.0391 \\
\hline Concordant (\%) & $\begin{array}{c}67.0(61 / 91) \\
{[7.4-76.7]} \\
\end{array}$ & $\begin{array}{c}53.8(49 / 91) \\
{[43.6-64.1]}\end{array}$ & 0.0042 & $\begin{array}{c}38.7(12 / 31) \\
{[21.6-55.9]} \\
\end{array}$ & $\begin{array}{l}19.4(6 / 31) \\
{[7.5-37.5]^{*}}\end{array}$ & 0.0313 & $\begin{array}{c}81.7(49 / 60) \\
{[71.9-91.5]} \\
\end{array}$ & $\begin{array}{c}71.7(43 / 60) \\
{[60.3-83.1]} \\
\end{array}$ & 0.1 \\
\hline Discordant (\%) & $\begin{array}{c}15.4(14 / 91) \\
{[8.0-22.8]} \\
\end{array}$ & $\begin{array}{l}9.9(9 / 91) \\
{[4.6-18.0]} \\
\end{array}$ & 0.0625 & $\begin{array}{l}12.9(4 / 31) \\
{[3.6-29.8]^{*}} \\
\end{array}$ & $\begin{array}{c}3.2(1 / 31) \\
{[0.1-16.7]^{*}} \\
\end{array}$ & 0.3 & $\begin{array}{c}16.7(10 / 60) \\
{[8.3-28.5]^{*}} \\
\end{array}$ & $\begin{array}{l}13.3(8 / 60) \\
{[5.9-24.6]^{*}}\end{array}$ & 0.5 \\
\hline \multicolumn{10}{|l|}{ Skeleton } \\
\hline Non-diagnostic (\%) & $\begin{array}{c}6.8(6 / 88) \\
{[2.5-14.3]^{*}}\end{array}$ & $\begin{array}{c}5.7(5 / 88) \\
{[1.9-12.8]^{*}}\end{array}$ & 1 & $\begin{array}{l}21.4(6 / 28) \\
{[8.3-41.0]^{*}}\end{array}$ & $\begin{array}{c}17.9(5 / 28) \\
{[6.1-36.9]}\end{array}$ & 1 & $\begin{array}{l}0(0 / 60) \\
{[0-6.0]}\end{array}$ & $\begin{array}{c}0(0 / 60) \\
{[0-6.0]}\end{array}$ & 1 \\
\hline Sensitivity (\%) & $\begin{array}{l}58.3(14 / 24) \\
{[36.6-77.9]^{*}}\end{array}$ & $\begin{array}{c}54.2(13 / 24) \\
{[34.3-74.1]}\end{array}$ & 1 & $\begin{array}{c}50(4 / 8) \\
{[15.7-84.3]^{*}}\end{array}$ & $\begin{array}{c}37.5(3 / 8) \\
{[8.5-75.5]^{*}}\end{array}$ & 1 & $\begin{array}{l}62.5(10 / 16) \\
{[35.4-84.8]^{*}}\end{array}$ & $\begin{array}{l}62.5(10 / 16) \\
{[35.4-84.8]^{*}}\end{array}$ & 1 \\
\hline Specificity (\%) & $\begin{array}{l}89.1(57 / 64) \\
{[78.8-95.5]^{*}} \\
\end{array}$ & $\begin{array}{l}89.1(57 / 64) \\
{[78.8-95.5]^{*}}\end{array}$ & 1 & $\begin{array}{c}75(15 / 20) \\
{[50.9-91.3]^{*}}\end{array}$ & $\begin{array}{c}75(15 / 20) \\
{[50.9-91.3]^{*}}\end{array}$ & 1 & $\begin{array}{l}95.5(42 / 44) \\
{[84.5-99.4]^{*}}\end{array}$ & $\begin{array}{l}95.5(42 / 44) \\
{[84.5-99.4]^{*}}\end{array}$ & 1 \\
\hline Concordant (\%) & $\begin{array}{c}80.7(71 / 88) \\
{[72.4-88.9]}\end{array}$ & $\begin{array}{c}79.5(70 / 88) \\
{[71.1-88.0]}\end{array}$ & 1 & $\begin{array}{l}67.9(19 / 28) \\
{[47.7-84.1]^{*}}\end{array}$ & $\begin{array}{c}64.3(18 / 28) \\
{[46.5-82.0]}\end{array}$ & 1 & $\begin{array}{l}86.7(52 / 60) \\
{[75.4-94.1]^{*}}\end{array}$ & $\begin{array}{l}86.7(52 / 60) \\
{[75.4-94.1]^{*}}\end{array}$ & 1 \\
\hline Discordant (\%) & $\begin{array}{c}12.5(11 / 88) \\
{[5.6-19.4]}\end{array}$ & $\begin{array}{c}14.8(13 / 88) \\
{[7.4-22.2]}\end{array}$ & 0.5 & $\begin{array}{c}10.7(3 / 28) \\
{[2.3-28.2]}\end{array}$ & $\begin{array}{c}17.9(5 / 28) \\
{[6.1-36.9]}\end{array}$ & 0.5 & $\begin{array}{l}13.3(8 / 60) \\
{[5.9-24.6]^{*}}\end{array}$ & $\begin{array}{l}13.3(8 / 60) \\
{[5.9-24.6]^{*}}\end{array}$ & 1 \\
\hline
\end{tabular}


1

2

3

4

7

8

10

11

12

13

14

15

16

17

18

19

20

21

22

23

24

25

26

27

28

29

30

31

32

33

34

35

36

37

38

39

40

41

42

43

44

45

46

47

48

49

50

51

52

53

54

55

56

57

58

59

60

61

62

63 


\section{Figure captions:}

Figure 1. Study flowchart and diagnosis of each organ group with post-mortem MR imaging at 1.5-T, 3-T and classical autopsy. AN: abnormal examination findings, $\mathrm{N}$ : normal examination findings, ND: non-diagnostic examination. The proportion of nondiagnostic cases at classical autopsy was significantly higher for the brain as compared to all other organ groups, while in the majority of fetuses, MR imaging with 1.5-T and 3-T was diagnostic for the brain.

Figure 2. Tissue contrast comparison at 1.5-T and 3-T post-mortem MR imaging showing a significantly increased contrast with $3-\mathrm{T}$ as compared with 1.5-T MR imaging for 9 out of the 14 studied ROI. The error bars are interquartile range (P2575). ROI: region of interest; GM: grey matter; Thal: thalamus; WM: white matter; Cart: cartilage; Musc: muscle; BP: blood pool; Myo: myocardium; Peff: pericardial effusion; PI: pleural effusion; Adre: adrenals; Cort: renal cortex; Pelvis: renal pelvis; *: $p<0.05$.

Figure 3. MRI at 1.5 T and 3-T of a fetus with Trisomy 13 and in utero fetal death at 41 weeks' gestation. T2-weighted turbo spin-echo image in a coronal view at the level of thoracic and abdominal structures with (A) $1.5 \mathrm{~T}$ and (B) 3-T showing better signalto-noise ratio at 3-T than $1.5 \mathrm{~T}$. Acquisition parameters for $1.5 \mathrm{~T}$ : Slice thickness $=2.0$ $\mathrm{mm}$; no intersection gap; TR/TE $=6800 \mathrm{~ms} / 127 \mathrm{~ms}$; Voxel resolution $=0.8 \times 0.5 \times 2.0$ $\mathrm{mm}^{3}$ ). Acquisition parameters for 3-T: Slice thickness $=1.3 \mathrm{~mm}$; no intersection gap; $\mathrm{TR} / \mathrm{TE}=5230 \mathrm{~ms} / 80 \mathrm{~ms}$; Voxel resolution $\left.=0.5 \times 0.6 \times 1.3 \mathrm{~mm}^{3}\right)$.

Figure 4. Correlation between diagnostic error and gestational age for each organ group and for both 1.5-T and 3-T MR imaging, showing significant inverse correlation for all organs with gestational age, except for the brain. The dotted line is the regression line for fetuses with 1.5-T and the solid line for 3-T MR imaging.

Figure 5. Box plots of the diagnostic error between 1.5-T and 3-T post-mortem MR imaging showing (A) for fetuses at $<20$ weeks of gestation significantly lower diagnostic error for all organ groups except for the brain and (B) for fetuses at $\geq 20$ weeks of gestation significantly lower diagnostic error for all organ groups except for the brain and face. The solid line within each box corresponds to the median. Upper and lower bars of boxes correspond to the first and third quartiles, respectively. Two vertical lines (whiskers) outside the box extend to the smallest and largest observations within 1.5 times the interquartile range of quartiles (interquartile range extends from the third quartile to first quartile). Circles are outliers corresponding to some false positive and false negative cases.

Figure 6. MRI at 1.5 T and 3-T of a fetus with left heterotaxia, terminated at 17 weeks' gestation. T2-weighted turbo spin-echo image in an axial view at the level of the 4chamber view with MRI at (A) $1.5 \mathrm{~T}$ showing a normal situs of the heart but hardly showing the cardiac anatomy and (B) 3-T showing an intraventricular septal defect (arrow). Acquisition parameters for $1.5 \mathrm{~T}$ : Slice thickness $=1.5 \mathrm{~mm}$; no intersection gap; TR/TE $=5680 \mathrm{~ms} / 109 \mathrm{~ms}$; Voxel resolution $\left.=0.8 \times 0.5 \times 1.5 \mathrm{~mm}^{3}\right)$. Acquisition parameters for 3-T: Slice thickness $=0.8 \mathrm{~mm}$; no intersection gap; TR $/ \mathrm{TE}=3620 \mathrm{~ms} /$ $80 \mathrm{~ms}$; Voxel resolution $=0.5 \times 0.6 \times 0.8 \mathrm{~mm}^{3}$ ).

Figure 7. MRI at 1.5-T and 3-T of a fetus with VACTERL association terminated at 36 weeks' gestation. T2-weighted turbo spin-echo image in an coronal view with MRI 1.5$\mathrm{T}(\mathrm{A})$ and 3-T (B) both showing dilated bowels with a mixture of amniotic liquid with meconium suggesting a distal obstruction and a pelvic kidney $\left(^{*}\right)$. Moreover, 3-T shows clearly the cervical hemivertebrae (arrow), which can be only suspected on the 1.5-T MRI. Acquisition parameters for $1.5 \mathrm{~T}$ : Slice thickness $=2.0 \mathrm{~mm}$; no intersection gap; 
$\mathrm{TR} / \mathrm{TE}=11000 \mathrm{~ms} / 127 \mathrm{~ms} ;$ Voxel resolution $\left.=0.8 \times 0.5 \times 2.0 \mathrm{~mm}^{3}\right)$. Acquisition parameters for $3-\mathrm{T}$ : Slice thickness $=1.5 \mathrm{~mm}$; no intersection gap; TR/TE $=6800 \mathrm{~ms} /$ $80 \mathrm{~ms}$; Voxel resolution $=0.5 \times 0.6 \times 1.5 \mathrm{~mm}^{3}$ ).

Figure 8. MRI at 1.5-T and 3-T of a fetus with congenital CMV infection inducing severe brain lesions terminated at 33 weeks' gestation. T2-weighted turbo spin-echo image in an axial view with MRI 1.5-T (A) and 3-T (B) both showing periventricular leucomalacia with microcalcifications (arrow), periventricular calcifications (open arrow), intraventricular septum (asterix) and gyration abnormalities (arrow head). Acquisition parameters for $1.5 \mathrm{~T}$ : Slice thickness $=2.0 \mathrm{~mm}$; no intersection gap; TR/TE $=11800 \mathrm{~ms} / 100 \mathrm{~ms} ;$ Voxel resolution $=0.8 \times 0.5 \times 2.0 \mathrm{~mm}^{3}$. Acquisition parameters for 3-T: Slice thickness $=1.5 \mathrm{~mm}$; no intersection gap; TR/TE $=15690 \mathrm{~ms} / 80 \mathrm{~ms}$; Voxel resolution $=0.5 \times 0.6 \times 1.5 \mathrm{~mm}^{3}$. 


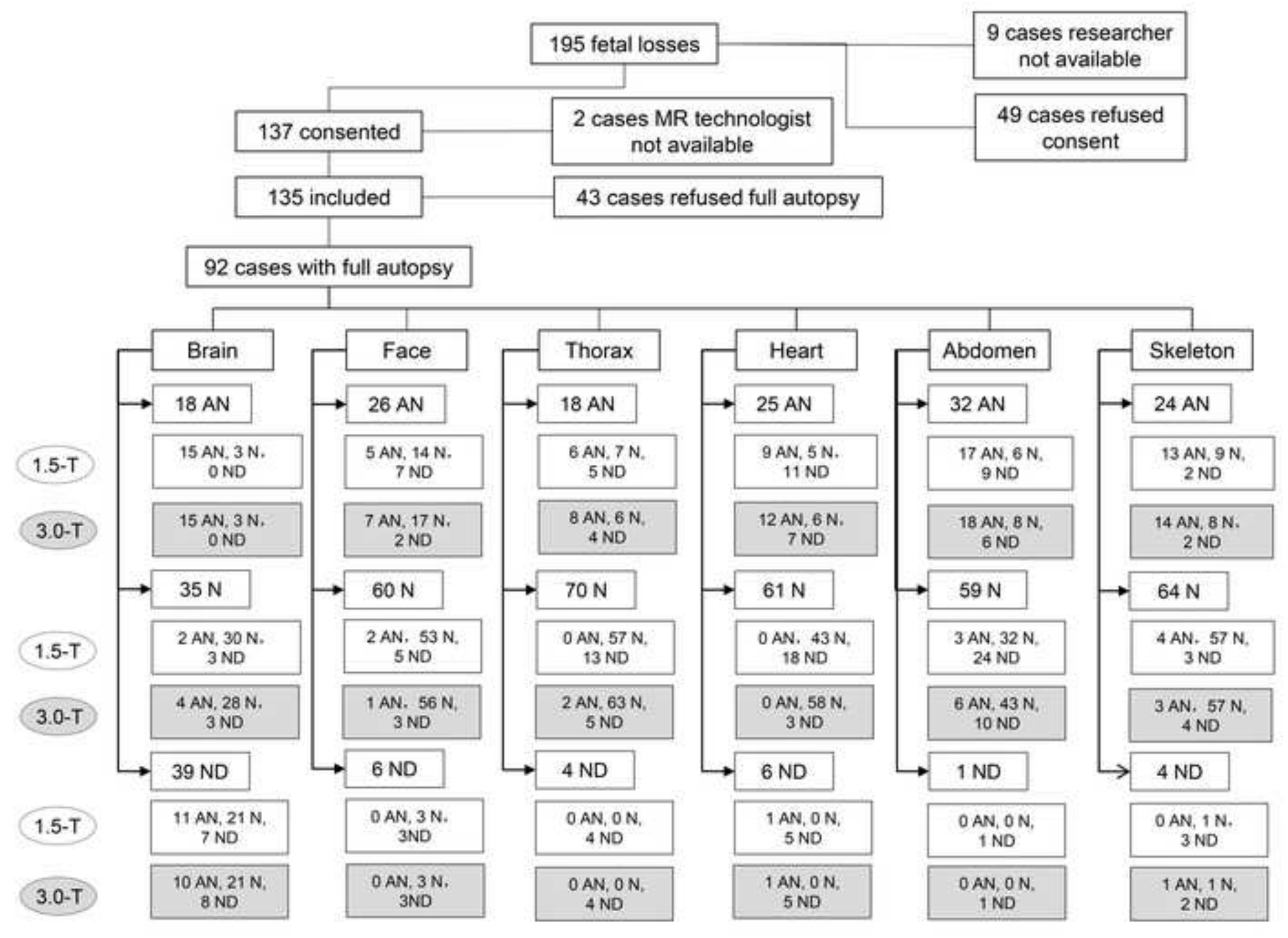

cases researcher

9 cases refused

consent 


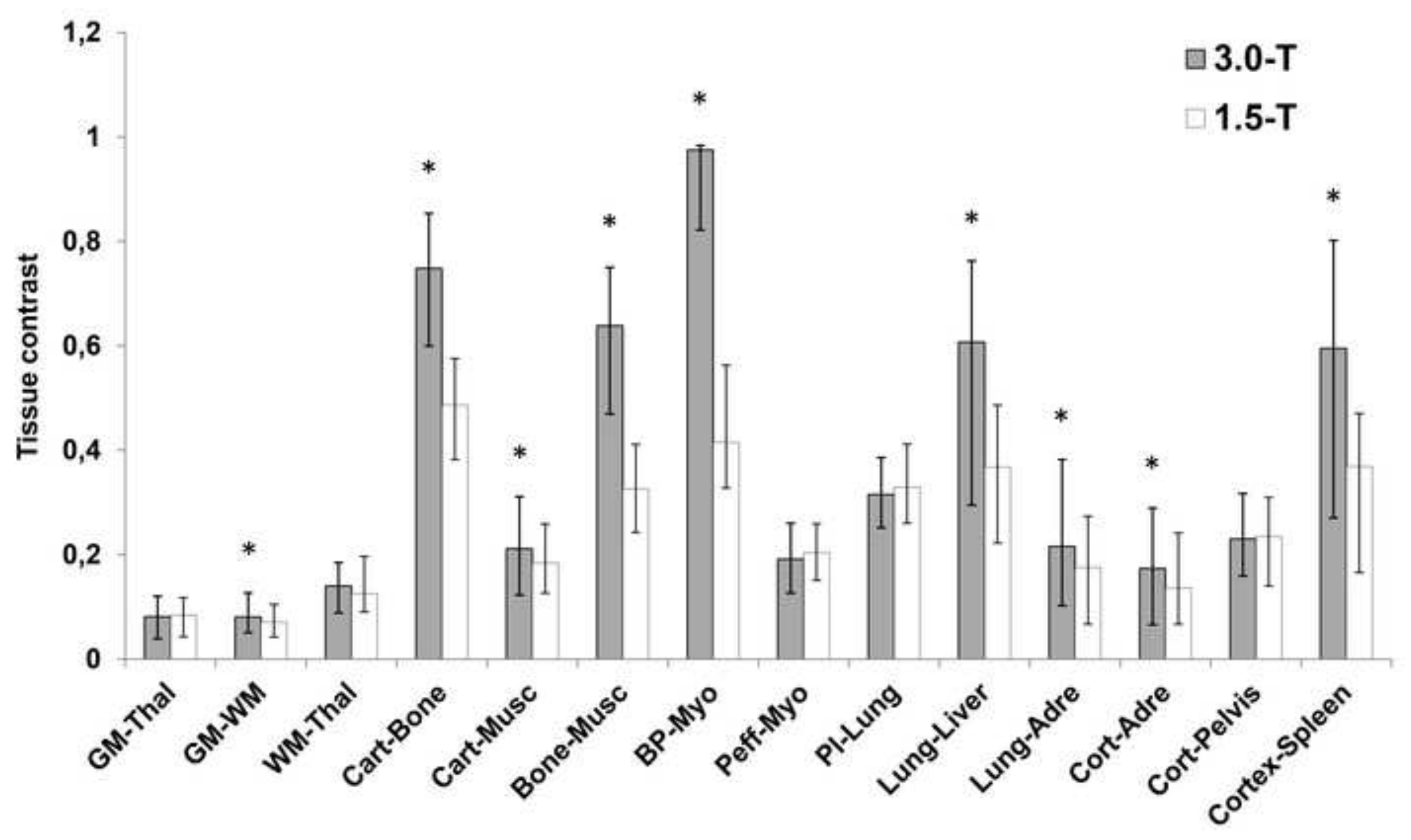



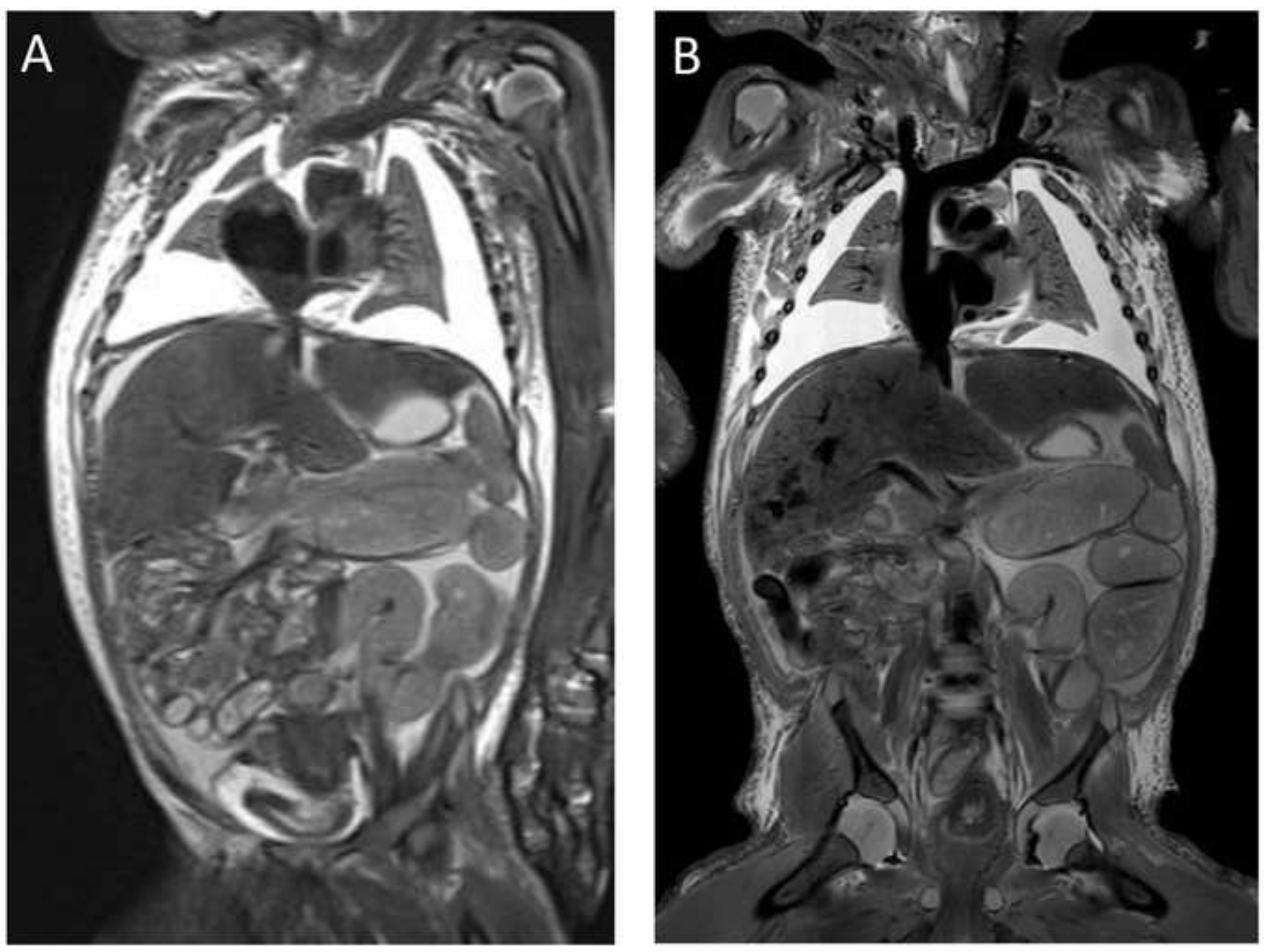


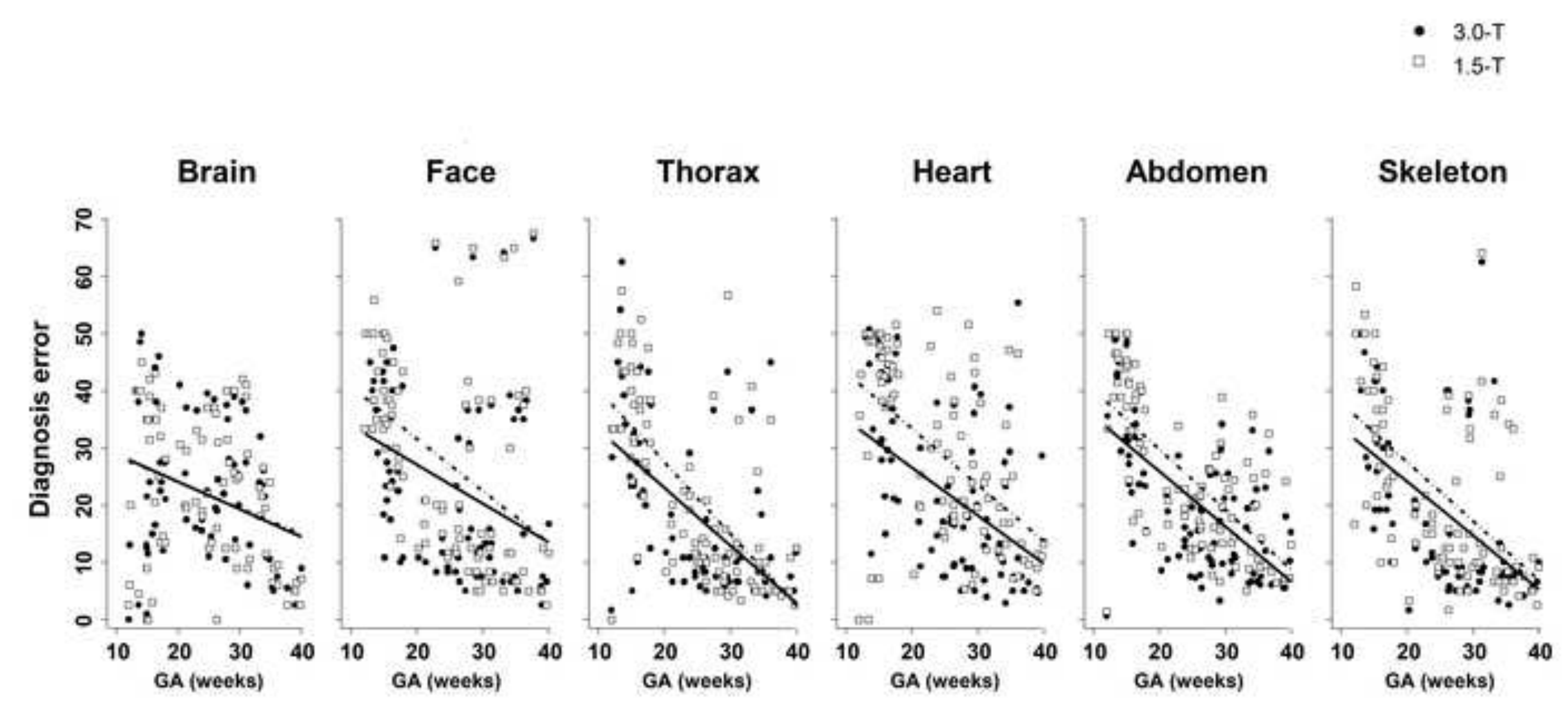



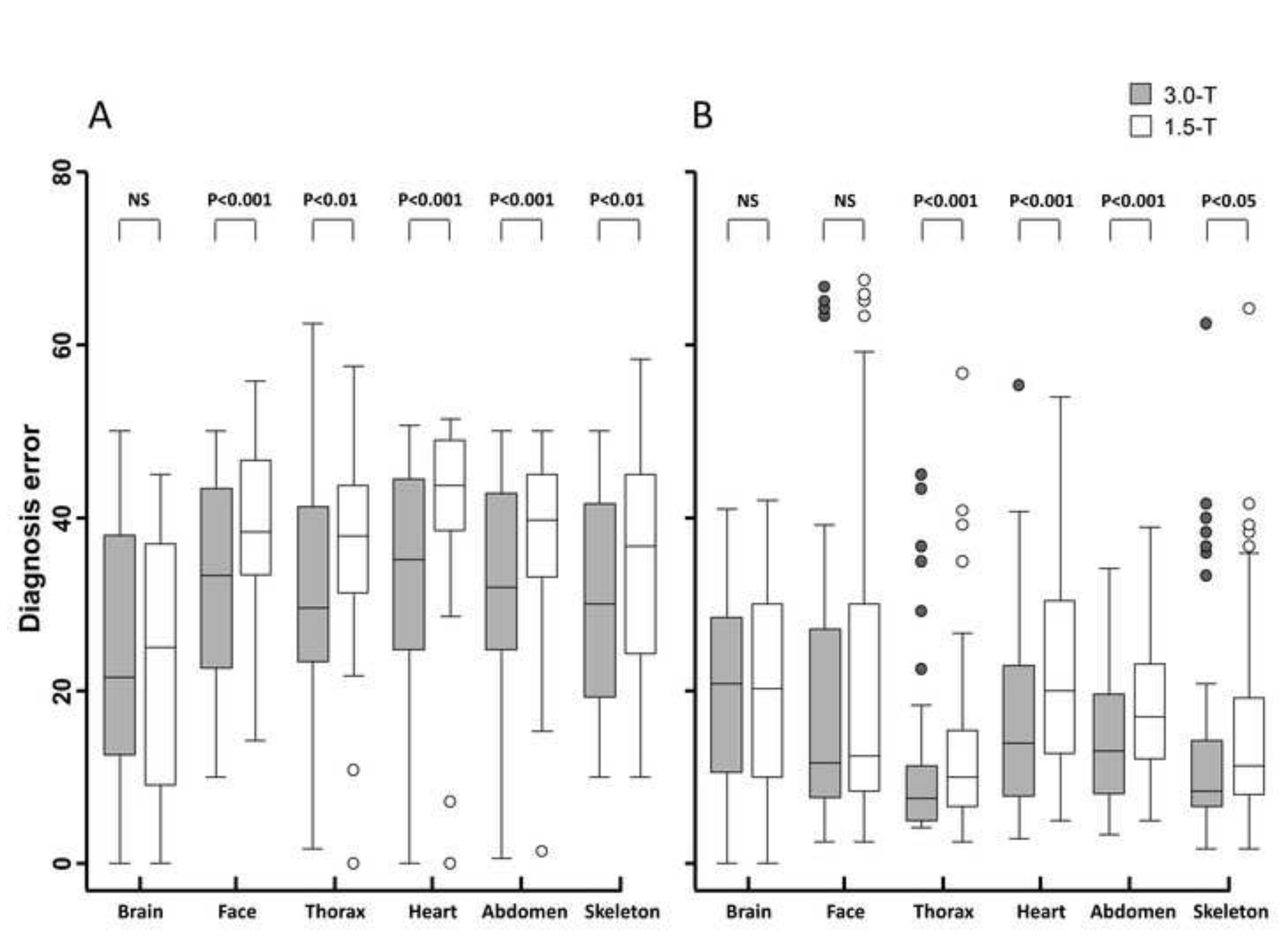
Click here to download Figure Fig6.tif $\underline{\underline{ }}$

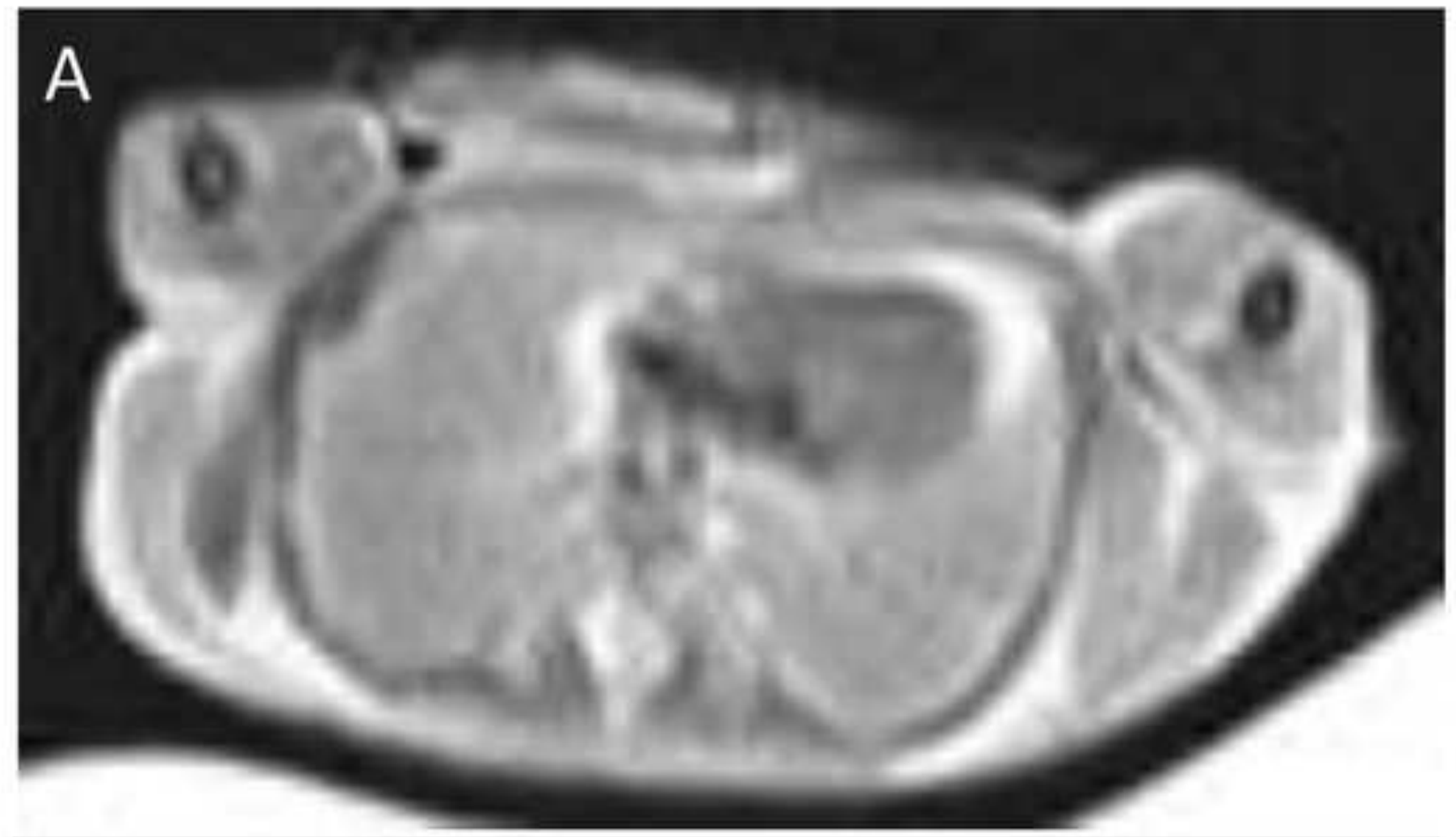

B

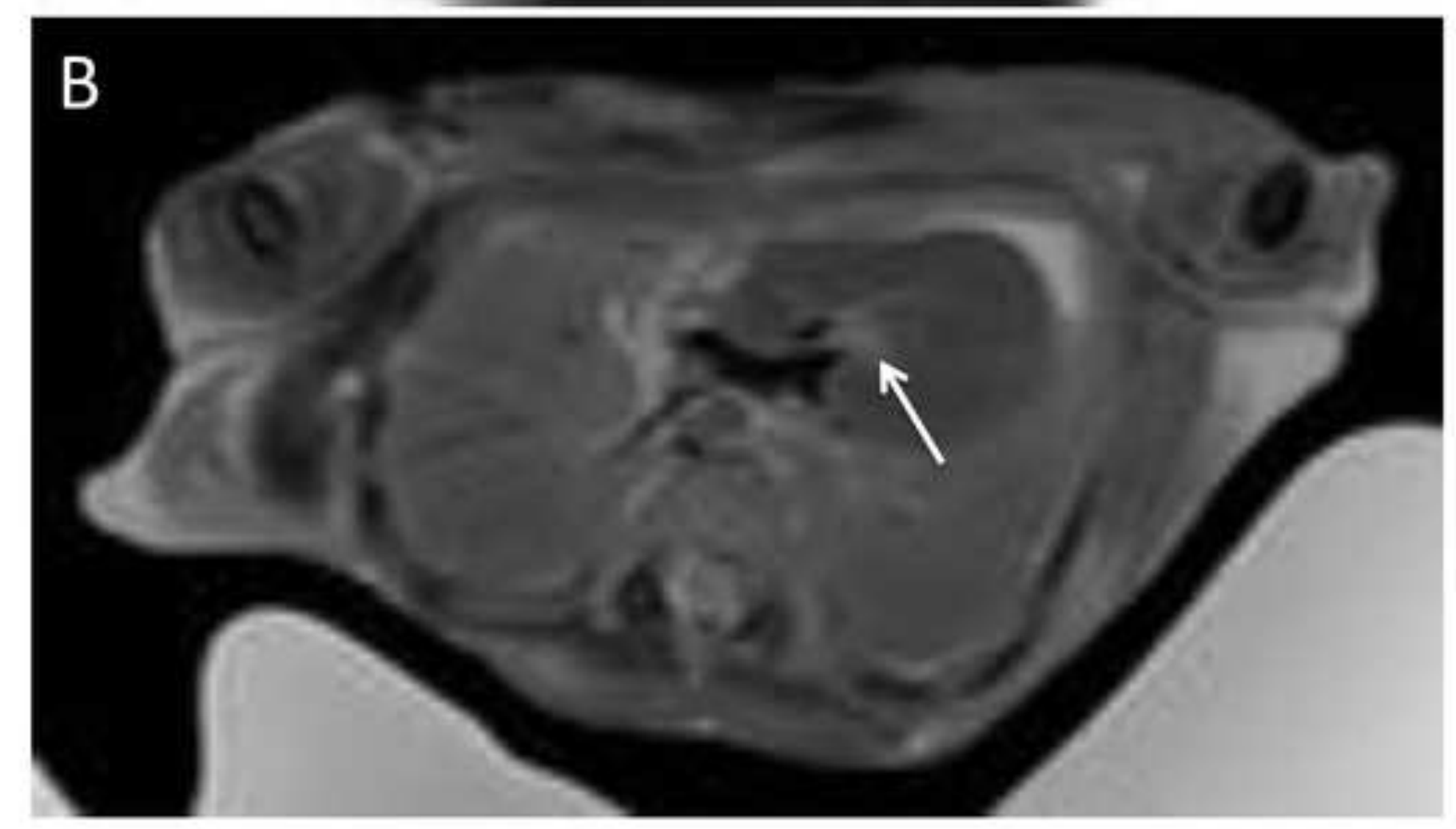



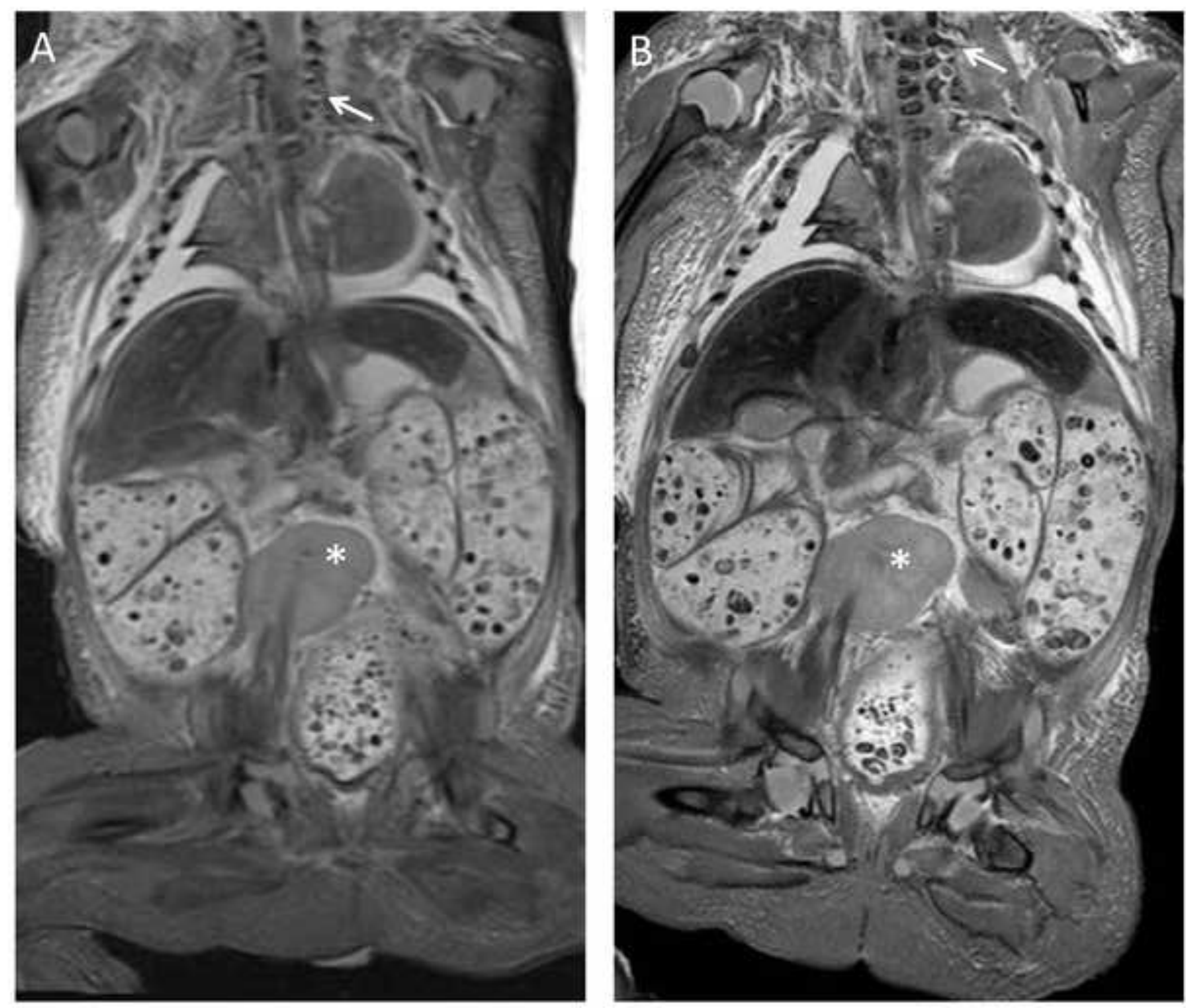
Click here to download Figure Fig8.tif $\underline{\underline{\underline{\iota}}}$
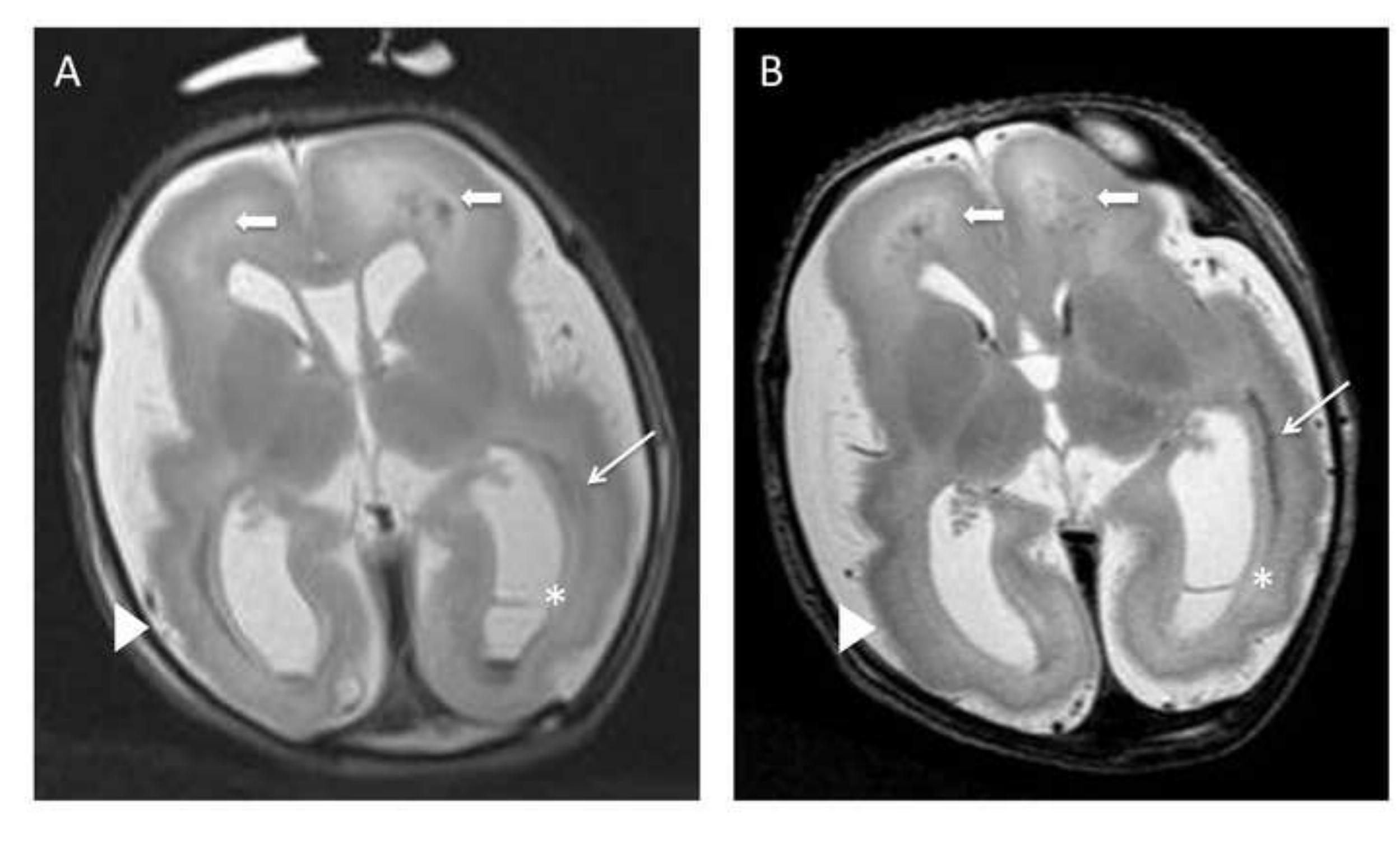


\section{Disclosure paragraph:}

1) The scientific guarantor of this publication is Xin Kang and Jacques Jani.

2) The authors of this manuscript declare no relationships with any companies, whose products or services may be related to the subject matter of the article.

3) This study has received funding by Fetal Medicine Foundation Belgium.

4) One of the authors has significant statistical expertise.

5) Institutional Review Board approval was obtained.

6) Only if the study is on human subjects:

Written informed consent was obtained from all subjects (patients) in this study.

9) Methodology:

- prospective

- observational

- performed at one institution 